\section{Mean Platelet Volume may not be Responsible for Aeti- ology in Patients with Idio- pathic Sudden Sensorineural Hearing Loss}

Sir,

We read with interest the retrospective study of Yildiz and Toros to evaluate haematological parameters in patients with idiopathic sudden sensorineural hearing loss (SSNHL). ${ }^{1}$ Since the number of cases with higher mean platelet volume (MPV) was more in the patient group than in the control group, the researchers suggested that this supports the role of vascular pathologies in patients with idiopathic SSNHL. We would like to express the existence of other factors that might have had a negative impacton the MPV results of this study.

MPV is a platelet parameter, whose measurement is still not standardised. ${ }^{2}$ The type of anticoagulant used, the time from blood collection to measurement, and the type of devices used in the measurement, may cause variability in MPV results. ${ }^{3,4}$ Whether the anticoagulant used is ethylenediaminetetraacetic acid (EDTA) or citrate changes the optimal MPV measurement time. ${ }^{5}$ The time from taking blood until measurement may lead to a change of $2-50 \%$, and the difference of the devices used in the measurement can cause deviation in MPV results of up to $40 \%{ }^{3,4}$ In this research, the type of anticoagulant used, the time of measurement, and the type of device used in the measurement, which are the main variables of MPV measurement standardisation, were not specified; and therefore, this affects the reliability of MPV results negatively. Likewise, the fact that the study was carried out retrospectively prevented the exclusion of pre-analytical and analytical errors. Moreover, the researchers used the MPV reference values as 4.5-8.5 fL and interpreted the pathological values in their research, according to the reference values they assumed. Depending on the methodological differences, MPV reference values of all laboratories vary; because of that the application of these reference values used, based on assumption, does not seem appropriate to interpret the MPV results of Yildiz and Toros' research.

As a result, MPV values may not be the sole responsible factor for aetiology in patients with idiopathic SSNHL.

\section{CONFLICT OF INTEREST:}

The authors declared no conflict of interest.

\section{AUTHORS' CONTRIBUTION:}

$\mathrm{CB}, \mathrm{EB}$ : Contributed to the conception and design of the work, material preparation, data collection and analysis. The manuscript was written, and commented on previous versions of the manuscript.
Both authors approved the final manuscript, accepted their responsibilities to ensure that questions related to any part or whole of the study are properly investigated and resolved.

\section{REFERENCES}

1. Yildiz S, Toros SZ. Vascular occlusion role in the etiopathogenesis of idiopathic sudden sensorineural hearing loss: Risk analysis with hematological parameters. J Coll Physicians Surg Pak 2020; 30(6):606-10. doi: 10. 29271/jcpsp.2020.6.606.

2. Noris P, Melazzini F, Balduini CL. New roles for mean platelet volume measurement in the clinical practice? Platelets 2016; 27(7):607-12. doi: 10.1080/09537104. 2016.1224828.

3. Jackson SR, Carter JM. Platelet volume: Laboratory measurement and clinical application. Blood Rev 1993; 7(2):104-13. doi: 10.1016/s0268-960x. (05)80020-7.

4. Lippi G, Pavesi F, Pipitone S. Evaluation of mean platelet volume with four hematological analyzers: Harmonisation is still an unresolved issue. Blood Coagul Fibrinolysis 2015; 26(2):235-7. doi: 10.1097/MBC.0000000000000220.

5. Lancé MD, van Oerle R, Henskens YM, Marcus MA. Do we need time adjusted mean platelet volume measurements? Lab Hematol 2010; 16(3):28-31. doi: 10.1532/LH96.10011.

Cengiz Beyan ${ }^{1}$ and Esin Beyan

${ }^{1}$ Department of Haematology, Faculty of Medicine, Ufuk University, Ankara, Turkey

${ }^{2}$ Department of Internal Medicine, Kecioren Training and Research Hospital, University of Health Sciences, Ankara, Turkey

Correspondence to: Dr. Cengiz Beyan, Department of Haematology, Faculty of Medicine, Ufuk University, Ankara, Turkey

E-mail: cengizbeyan@hotmail.com

Received: July 28, 2020; Revised: July 30, 2020;

Accepted: August 24, 2020

DOI: https://doi.org/10.29271/jcpsp.2021.07.877

\section{AUTHOR'S REPLY:}

Sir,

We are grateful for the authors' comment on our article studying the role of vascular occlusion in the etiopathogenesis of idiopathic sudden sensorineural hearing loss (SSNHL). ${ }^{1}$ We thank the authors for drawing attention to the effect of the method or devices used in complete blood count (CBC). Initially, we agree with the authors on the methodological concern of mean platelet volume (MPV) evaluations. In many laboratories, it is common to have a time gap between venipuncture and sample analysis. ${ }^{2}$ Blood samples should be examined within 2 hours to 
avoid erroneous results due to ethylene diamine tetraacetic acid (EDTA) or citrate. ${ }^{3}$ In addition, different CBC devices can generate different MPV results. ${ }^{4}$

Although our study had a retrospective design, but since it covered a short period of time, the individuals included in the study had been standardised in terms of the factors aforementioned. Laboratory analyzes in our hospital are evaluated according to the standard procedures of our clinical pathology departments. Results are given within two hours. Blood samples were taken into EDTA tubes. To analyse the $C B C$, the same device (Beckman Coulter-T540, Beckman Coulter, Brea, CA, USA) was used in the study in which we took the MPV reference range as a sample. ${ }^{5} \mathrm{MPV}$ values of all subjects and controls were measured similarly in both groups. We found statistically significant changes among the groups. ${ }^{6}$ That is why, we thought that our findings are important. We believe our results provide valuable findings and framework for future research. More prospective studies are required to verify our results.

\section{REFERENCES}

1. Beyan C, Beyan E. Mean platelet volume may not be responsible for aetiology in patients with idiopathic sudden sensorineural hearing loss. J Coll Physicians Surg Pak 2021; 30(7).

2. Perez I, Redin ME. Red blood cells and platelets conventional and research parameters: Stability remarks before their interpretation. Lab Med 2020; 51(5):460-8. doi: 10.1093/labmed/lmz083.

3. Dastjerdi MS, Emami T, Najafian A, Amini M. Mean platelet volume measurement, EDTA or citrate? Hematology 2006; 11(5):317-9. doi: 10.1080/10245330600954163.

4. Lance' MD, van Oerle R, Henskens YM, Marcus MAE. Do we need time adjusted mean platelet volume measurements? Lab Hematol 2010; 16(3):28-31. doi: 10.1532/LH96.10011.

5. Bancroft AJ, Abel EW, Mclaren M, Belch JJ. Mean platelet volume is a useful parameter: A reproducible routine method using a modified Coulter thrombocytometer. Platelets 2000; 11(7):379-87. doi: 10.1080/0953710 0020008311.

6. Yıldız S, Zer Toros S. Vascular occlusion role in the etiopathohegenesis of idiopathic sudden sensorineural hearing loss: Risk analysis with hematological parameters. J Coll Physicians Surg Pak 2020; 30(6):606-10. doi: 10.29271/jcpsp.2020.6.606.

Selçuk Yildiz

Department of Otorhinolaryngology, Head and Neck Surgery, Haydarpaşa Numune Training and Research Hospital, Istanbul, Turkey

Correspondence to: Department of Otorhinolaryngology, Head and Neck Surgery, Haydarpaşa Numune Training and Research Hospital, Istanbul, Turkey

E-mail: selcukyildiz60@hotmail.com 